\title{
CHILDREN'S TRUST IN THE TESTIMONY OF PHYSICALLY DISABLED OR OBESE INDIVIDUALS
}

\author{
by \\ Sara Jaffer \\ Honours Bachelor of Science in Psychology, University of Toronto, June 2012 \\ A thesis \\ presented to Ryerson University \\ in partial fulfillment of the \\ requirements for the degree of \\ Master of Arts \\ in the Program of \\ Psychology
}

Toronto, Ontario, Canada, 2014

(c) Sara Jaffer 2014 


\section{AUTHOR'S DECLARATION FOR ELECTRONIC SUBMISSION OF A THESIS}

I hereby declare that I am the sole author of this thesis. This is a true copy of the thesis, including any required final revisions, as accepted by my examiners. I authorize Ryerson University to lend this thesis to other institutions or individuals for the purpose of scholarly research. I further authorize Ryerson University to reproduce this thesis by photocopying or by other means, in total or in part, at the request of other institutions or individuals for the purpose of scholarly research. I understand that my thesis may be made electronically available to the public. 
Children's Trust in the Testimony of Physically Disabled or Obese Individuals

Sara Jaffer

Master of Arts, 2014, Psychology, Ryerson University

\begin{abstract}
Previous research has examined various factors that influence children's trust in testimony. However, no studies have yet looked at children's willingness to trust physically disabled or obese individuals. Evidence shows that children's perception of the physically disabled may be both positive and negative, whereas their perception of overweight individuals is negative.

Given these attitudes, Study 1 examined the possibility that children may place less trust in these individuals and their testimony. Four- and 5-year-old children were asked to endorse the testimony of one speaker (physically abled and non-obese vs physically disabled/obese) when conflicting testimony was provided. The results showed that children favoured the testimony of the physically abled and non-obese individual at a level significantly above chance. In Study 2 , physical condition was pitted against past reliability, and 4- and 5-year-olds were asked to choose between a previously unreliable physically abled and non-obese individual or a previously reliable physically disabled or obese individual. The results indicated that overall children did not show a significant preference for one individual over another. In line with previous findings on children's negative perceptions of physically disabled and obese individuals, children place less trust in their testimony, and past reliability might cancel out this effect.
\end{abstract}




\section{Acknowledgements}

I am grateful to the children and parents whose participation made this research possible. I also want to thank the Ontario Science Center (especially Sara Porier), for their generous support for participant recruitment. I also thank my supervisor Dr. Lili Ma for her constant support, guidance and comments throughout the development of this paper. I would also like to thank the research assistants at the Ryerson Early Childhood Cognition Lab, especially Melissa Harilal and Megan Ruhig for their assistance in data collection and coding. 
Table of Contents

Page Number(s)

Introduction

$1-12$

Study 1

$13-26$

Study 2

$27-33$

General Discussion

34-41

References

$42-49$ 


\section{Introduction}

As children develop they acquire knowledge about the world through directly observing and experiencing the events around them. However, there are many domains that they cannot learn about through direct experiences such as past historical events or space and time (Harris, 2007). Thus, much of the information they acquire is through the testimony of close others such as parents, teachers, and peers (Harris, 2007; Koenig \& Harris, 2005). Some developmental psychologists neglect to study the importance of testimony in learning because they view the child as an active scientist that explores and develops ideas about the world through experimentation, not testimony (Piaget, 1929). However, it is through both experimentation and the testimony of others that the child gathers knowledge about different phenomena as they develop (Harris, 2002).

Since children gather knowledge through the testimony of others, there is a large amount of research focusing on children's willingness to trust the testimony of others. By the age of 4, children are skeptical when assessing testimony because they take into account an informant's previous reliability (Clement, Koenig, \& Harris, 2004; Einava \& Robinson, 2010; Jaswal \& Neely, 2006; Koenig \& Harris, 2005; Koenig, Clement, \& Harris, 2004; Liu, Vanderbilt, \& Heyman, 2013; Ma \& Ganea, 2010; Scofield, Gilpin, Pierucci, \& Reed, 2013), bystanders' reactions to the testimony (Chudek, Heller, Birch, \& Henrick, 2011; Fusaro \& Harris, 2008), and the informant's gender (Ma \& Woolley, 2013), age (Jaswal \& Neely, 2006) and accent (Kinzler, Corriveau, \& Harris, 2011). Although the previous research has addressed the relationship between these characteristics and trust, children's willingness to trust physically disabled or obese individuals has not yet been examined. This is an important issue to study because 
children's negative and mixed attitudes toward these individuals will influence how children react and behave toward these individuals in the future.

Even though the trustworthiness of physically disabled and obese individuals has not been studied, social evaluation literature has provided insight into how they are commonly perceived by children. Children's early perceptions and attitudes toward physically disabled individuals have been found to be mixed (Dyson, 2005; Nowicki \& Sandieson, 2002; Spillers, 1982), and attitudes toward obese individuals have been negative (Cramer \& Steinwert, 1998; Kraig \& Keel, 2001; Wei \& Di Santo, 2011; Tiggeman \& Anesbury, 2000; Tillman, Kehle, Bray, Chafouleas, \& Grigerick, 2007; Turnbull, Heaslip, \& Mcleod, 2000).

Given these mixed attitudes towards physically disabled individuals and negative attitudes towards obese individuals, it is possible that children may place less trust in these individuals as a source of information. The proposed study examined this possibility to provide more insight into children's trust of these individuals. This paper will first review the literature on children's development of trust and their perceptions and attitudes towards physically disabled and obese individuals. Next, Study 1 examined children's willingness to trust physically abled and non-obese versus physically disabled or obese individuals when they provided conflicting testimony about domain-specific or domain-general knowledge. Study 2 examined if children's preference for the physically abled and non-obese individuals would persist even when they had been proven to be unreliable in the past.

\section{Literature Review}

\section{Trust}

Although children may have a natural inclination to trust the testimony of others (Dawkins, 1995; Gilbert, 1991), one must consider if children believe all things they are told, or 
if they are selective in whom they trust. Some research demonstrates that 3-year-olds and some 4-year-olds may not have the cognitive capabilities to realize that their own or others' beliefs could be false (Wellman, Cross, \& Watson, 2001), and may be credulous to false claims in early childhood (Dawkins, 1995; Ma \& Ganea, 2010). However, this is debated because at the ages of 3-5, children are already able to identify the source of their beliefs and are able to articulate from where and whom they learnt certain information (Gopnik \& Graf, 1988). The question arises as to whom children will be inclined to trust and learn from when exposed to people providing conflicting testimony about the same topic. Research shows that when deciding whom to trust, children assess factors such as: informants' previous accuracy of testimony, bystander reactions to the testimony provided, and the social group to which the informant belongs. Research pertaining to each of these factors will be examined below in more detail.

Accuracy. Past research has examined whether or not children blindly accept the claims of others, or if they cautiously assess the information they are given for its accuracy. Preschoolers have been found to trust informants that have previously been accurate in their testimony (Clement et al., 2004; Einava \& Robinson, 2010; Jaswal \& Neely, 2006; Koenig \& Harris, 2005; Koenig et al., 2004; Liu et al., 2013; Scofield et al., 2013) and continued to remember and endorse the testimony of a previously reliable informant after one week, without any explicit cues or prompts (Corriveau \& Harris, 2009).

A study conducted by Koenig, Clement and Harris (2004) first examined if children could track the accuracy of a person's testimony regarding familiar objects. In the familiarization trials, the child watched video clips of two informants providing conflicting names for familiar objects such as a ball, cup and book. Then, in the first explicit judgement trial, half the children 
were asked to identify which person was right when naming the objects, and the other half were asked to identify which informant was wrong in their labelling of the objects. The researchers found that both 3- and 4-year-old children were very good at distinguishing between accurate and inaccurate informants. Next, the children watched novel test trials to see if they would use an informant's previous accuracy to trust their testimony when learning new information. The novel trials were the same as the familiarization trials except novel objects were presented and the informants provided unknown names (e.g. mido, toma) to label the objects. Then, in the second explicit judgement trial, the child was again asked which person they believed labelled the objects correctly or incorrectly. The researchers found that children preferred to endorse testimony in the novel trials from speakers that were previously accurate in the familiarization trials. This demonstrates that children were able to keep track of the accuracy of claims made by informants and use this information to choose whom to learn from later on.

It is also of interest to examine if children are able to track the relative accuracy of a person's claims, and if they are able to differentiate between informants that were accurate in the majority of their claims as opposed to those that were not. A study conducted by Pasquini et al. (2007) found that 4-year-olds were able to differentiate between informants that were $75 \%$ accurate from an informant that was only $25 \%$ accurate, and preferred to seek information from the more accurate one. However, 3-year-olds were unable to do this and only showed selective trust when the informants were correct $100 \%$ of the time. It is speculated that 3 -year-olds show this behaviour because they first categorize both informants as trustworthy but deem one to be untrustworthy after one inaccurate claim is made. This categorization may be the reason that 3year-olds only view an accurate informant as one who is correct all the time, and not only the majority of the time. 
In addition to choosing reliable informants when learning novel information about objects, children also prefer to endorse the testimony of accurate speakers to guide their future word use (Birch, Vauthier, \& Bloom, 2008; Scofield \& Behrend, 2008), learning of game rules (Rakoczy, Warneken, \& Tomasello, 2009) and behaviour (Scofield et al., 2013).

A study by Ma and Ganea (2010) examined if 3- to 5-year-old children would rely on their own direct observations of an object's location or the false testimony of an adult when completing an object search task. In Study 1, children observed from behind a window as an experimenter hid a toy in a blue bucket, a red bowl, or a purple box. After hiding the toy, the experimenter provided false testimony to the child regarding the object's location. For example, the child may have directly observed the experimenter hiding the toy in the blue bucket, but the experimenter testified that the object was hidden in the purple box. The researchers found that 3 year-olds believed the false testimony and disregarded their own observations when searching for the hidden object. However, 4- and 5-year-old children relied on their own observations when searching and disregarded the false testimony. Studies 2 and 3 showed that with either a prior successful searching experience based on their own direct observations or with a single prior exposure to the adult as an unreliable source of information, 3- and 4-year-olds became skeptical of the adult's false testimony and relied on their own observations to find the object. Thus, children may be initially credulous toward another person's false testimony that is obviously false, but skepticism can be quickly developed through experience.

The studies above demonstrate that children do not in fact blindly accept the claims of others, but rather take time to assess the reliability of an informant when testimony is provided. The accuracy of a speaker's testimony plays an important role when children evaluate claims and many research studies have consolidated the research findings that children trust previously 
reliable informants more than unreliable informants (e.g., Clement et al., 2004; Jaswal \& Neely, 2006; Liu et al., 2013).

Bystander approval. In addition to accuracy, children may use other sources such as bystanders' reactions to a speaker's claims, to determine an informant's trustworthiness. Fusaro and Harris (2008) found that children were sensitive to bystanders' reactions to information provided by two informants. More specifically, 4-year-olds endorsed the testimony of an informant that provided novel information, when their claims were nonverbally supported (e.g., head nodding) by bystanders. Also, they viewed the testimony of the informant as unreliable when it was nonverbally disapproved (e.g. head shaking) of by bystanders. They further continued to support the informant's claims even when the bystanders were not present, which demonstrated that children attributed reliability to the informant that was previously supported by others.

Chudek, Heller, Birch, and Henrick (2011) also investigated children's endorsement of learning from bystanders reactions, by examining "prestige bias". Prestige bias is when an individual prefers to learn information from others that have previously been learned from or attended to by others. The researchers found that preschooler's showed prestige bias by preferring to learn from models that bystanders gazed at and attended to more. They also found that even when the bystanders were not present, children were twice as likely to learn from the model that was previously attended to by the bystanders, than models that were not attended to.

Social groups. Children are also aware of the social groups to which people belong, which may influence the amount of trust they exhibit toward certain individuals. One such social category that may influence children's trust of others is the gender of the speaker. At approximately age 3 , children show a strong preference for socializing with same sex peers 
(Martin \& Fabes, 2001) and an increased preference to play exclusively with others of the same gender (Fabes, Shepard, Guthrie, \& Martin, 1997; Martin \& Fabes, 2001). Also, when observing different contradictory behaviours, children prefer to watch and imitate actors of the same gender (Bussey \& Bandura, 1984; Grace, David, \& Ryan, 2008). This strong preference to play with and imitate same sex others, demonstrates children's bias toward same-gender others. This bias may also be evident when children begin to learn novel information through the testimony of others. A study conducted by Ma and Woolley (2013) demonstrated that when learning novel information, 4- and 6-year-old children showed a preference for learning from the testimony of same-gender speakers. The researchers also found that when provided with testimony regarding novel objects of different colours (e.g. blue and pink), children preferred to learn from the speaker associated with the gender-stereotypical colour.

Another social category that may influence children's trust is the age of an individual. Many studies show that children are very aware of what people of different ages may know, and view adults as more knowledgeable about the world than themselves (Burton \& Mitchell, 2003; Taylor, Cartwright, \& Bowden, 1991). Due to believing that adults are more knowledgeable about phenomena, children may place more trust in adults even if their past accuracy is unknown. This is demonstrated in a study conducted by Jaswal and Neely (2006) where they found that preschoolers prefer to endorse adult testimony in comparison to child testimony, when they are unaware of the past reliability of the speaker. However, when the adult speaker was unreliable whereas the child speaker was reliable in the past, children preferred to endorse the testimony of a peer.

Although a person's accent is not a distinct social category, it may serve as a cue to one's social category or to the group to which an individual belongs. Children may be sensitive to a 
speaker's accent when they are providing testimony, which may serve as a signal to the child if the speaker is from their community or from a different area. A study conducted by Kinzler, Corriveau and Harris (2011) demonstrated that 4- and 5- year-old children were more likely to seek and trust non-verbal information from a native-accented rather than a foreign-accented speaker. They also displayed this preference both when the informants spoke naturally and when they spoke nonsensical language, prior to exhibiting non-verbal information.

The literature reviewed above demonstrates that there are many characteristics that influence whom children choose to trust, such as an informant's previous reliability, bystander reactions to testimony provided, and social groups such as age and gender. One area that previous research fails to address is whether an informant's physical characteristics, such as a physical disability or being obese, would have an impact on children's acceptance of their testimony. Although children's willingness to trust physically disabled and obese individuals has not been examined, past research has examined children's attitudes toward them. This research will be examined in the next section in more detail.

\section{Perception of Physically Disabled Individuals}

Although the perceived trustworthiness of physically disabled and obese individuals has not been examined, social evaluation literature has provided insight into how they are commonly perceived by children. The current literature provides mixed findings on children's attitudes towards people with different types of disabilities (Dyson, 2005; Nowicki \& Sandieson, 2002; Spillers, 1982). Some research indicates that during the preschool years, children begin to develop negative reactions to those that appear physically different from themselves (Favazza \& Odom, 1997). However, some researchers claim that these negative attitudes do not persist and attitudes toward disabled children tend to become more positive over the childhood years 
(Spillers, 1982), which could be due to attitudes aligning with the society's and parental values (Richardson, 1970). Although attitudes may be positive, Magiati, Dockrell and Logotheti (2002) found that 7- to 11-year-old children's positivity toward the physically disabled declined when considering personal involvement in activities with them. Although this research has demonstrated the existence of negative and positive attitudes toward physical disabilities, the link between these two still remains unclear (Harper, 1997; Okagaki, Diamond, Kontos, \& Hestenes, 1998).

The relationship between children's attitudes toward physical disabilities was most thoroughly assessed in various studies conducted by Richardson and colleagues. Richardson, Goodman, Hastorf, and Dornbusch (1961) showed that children's preference for a person increased as their disability moved further from their face. It was hypothesized that this was the case because in our society, the face provides a very important initial assessment of a person. Their later study examined children's attitudes towards the physically disabled by requiring them to rank disabled characters from most to least liked. It was found that children preferred (from most to least) the non-disabled child, child with crutches/brace, child in a wheelchair, child without a hand, child with a facial abnormality, and an obese child. Even children with a physical handicap ranked their preferences in the same way that the non-handicapped children did (Richardson, 1983).

Richardson's studies produced some interesting gender effects when assessing attitudes toward physical disabilities. Girls were found to be less positive toward the child with a facial disfigurement and more positive to those in a wheelchair, whereas the boys were found to be more positive to those with facial disfigurements and obesity (Richardson, 1983; Richardson, Goodman, Hastorf, \& Dornbusch, 1961). This finding was also replicated by Sigelman, Miller 
and Whitworth (1986): They hypothesized that this gender effect was due to society emphasizing the importance of physical ability among boys and physical appearance among girls. It is important to note that in all the studies, the obese child was least liked in comparison to the physically abled and non-obese and physically disabled children across all ages and both genders. This finding is important to investigate further because obesity is widely prevalent and is drastically increasing in our society (Deckelbaum \& Williams, 2012).

\section{Perception of Obese Individuals}

Since there is a great importance placed on physical appearance at a young age, overweight and obese children are at risk for being stigmatized (Weil, 1977). Children are aware of differing body types at approximately 3-4 years of age and are able to categorize individuals on weight and figure (White, Mauro \& Spindler, 1985 as cited in Powlishta et al., 1994). At age 5, children have been shown to positively associate a mesomorph body type as being similar to themselves and to positive word categories (Lerner \& Gellert, 1969; Lerner \& Korn, 1972), regardless of their own body build (Lerner \& Korn, 1972; Staffieri, 1967). When relating positivity with a mesomorph body type, children consequently viewed and labelled other body types unfavourably. This was seen when Staffieri (1967) found that 6- and 7-year-old boys preferred to look at mesomorph images but when they viewed endomorphic obese images, they labelled them negatively by calling them sloppy or sneaky. Several studies examining children as young as 3 years old have also found this trend, where overweight children are viewed as being mean, lazy, unattractive, unhappy, unpopular or unfriendly (Cramer \& Steinwert, 1998; Kraig \& Keel, 2001; Wei \& Di Santo, 2011; Tiggeman \& Anesbury, 2000; Tillman et al., 2007; Turnbull et al., 2000) and as being less intelligent compared to normal weighted individuals (Kraig \& Keel, 2001). To further examine these findings and apply them to a realistic scenario, Birbeck 
and Drummond (2005) asked 5- and 6-year-old children to choose 3 out of 9 people with differing body types that they would want to invite to their birthday party. The researchers found that the people with larger body types were stigmatized and were not chosen to be invited. Furthermore, children provided various reasons for their choices, as they explained that the images with larger figures were "mean, bullies and nasty". In relation to these findings, Goldfield and Chrisler (1995) found that when first graders were asked whom they most identified with in terms of appearance, and whom they would choose as friends, they were least likely to select an obese child.

As mentioned above, Richardson et al. (1961) found that physically abled and non-obese and physically disabled children both ranked an obese child least favourably in comparison to normal and physically impaired children. A replication of this study was done to examine if these findings would still occur given that the study was conducted four decades prior. In fact, Latner and Stunkard (2003) found that the stigmatization was even stronger in their study in comparison to Richardson's. They found that the normal and facially disfigured children were liked more than they previously were, and the obese child was even more disliked and stigmatized against by 10 - and 11-year-old children. This study shows that even though the stigmatization of facially disfigured children has decreased in the past 40 years, this has not been the case for obese children. Researchers have hypothesized that this stigmatization may still be high because people feel that obese individuals are to blame for their weight (Tiggemann \& Anesbury, 2000). This may create the perception that children with disabilities do not have a choice about their condition, but that obese individuals have chosen to be overweight due to their poor habits and personal choices. 
The literature examined above shows that children's perception of the physically disabled may be both positive and negative (Dyson, 2005; Nowicki \& Sandieson, 2002; Spillers, 1982). However, children's perceptions of overweight individuals are negative as children attribute many negative traits to them (e.g., Cramer \& Steinwert, 1998; Wei \& Di Santo, 2011; Tillman et al., 2007). Given these negative attitudes towards physically disabled and obese individuals, it is possible that children may place less trust in these individuals as a source of information. The present study examined this possibility.

\section{The Present Study}

The research outlined above has addressed the areas of the development of trust in children and of their perceptions of physically disabled and obese individuals. The trust literature has only examined children's willingness to trust the testimony of others based on their past accuracy, the endorsement of their testimony by bystanders, their gender, age, and accent. However, a gap remains in the literature where children's willingness to trust the testimony of physically disabled and obese individuals has not yet been examined. Therefore, in order to contribute to the research on trust and social perception, the present study aimed to investigate children's willingness to trust these physically different individuals.

More specifically, this study examined children's trust of physically abled and non-obese versus physically disabled or obese individuals when they provided conflicting testimony regarding domain-specific and domain-general knowledge. Study 1 first examined domainspecific (DS) knowledge that was directly related to an individual's physical disability. For example, this could be knowledge about a sport that would be directly related to a wheelchair bound individual's disability and others' perceptions of their ability to engage in the activity. Study 1 also examined domain-general (DG) knowledge that was about general information and 
was perceived to be unrelated to the individual's physical disability, for example, knowledge about animals. It was hypothesized that 4- and 5-year-old children would respond similarly and choose to trust the physically abled and non-obese adult when domain-specific knowledge was presented. The rationale for this can be examined through viewing the literature on the cognitive division of labour.

The phenomenon of the cognitive division of labour has been studied in regards to children speculating if adults possess certain knowledge based on their gender or professions. At a young age children begin to understand that everyone is not equally knowledgeable and that each individual may only have a particular area of expertise about which they are educated (Koenig \& Jaswal, 2011). For example, a study by Ma and Woolley (2013) showed that children were sensitive to the fact that one gender over the other may be a better source of information regarding gender stereotypic knowledge. Also, a study by Lutz and Keil (2002) found that children as young as 3 years of age were aware of the differing types of information that a doctor would know as opposed to a mechanic.

Study 1 investigated if children would extend the cognitive division of labour theory to encompass an individual's physical characteristics. More specifically, it was of interest to examine if children would assume that the physically disabled or obese individuals were unknowledgeable about domains pertaining to their disabilities (e.g. playing sports, painting) because they were perceived to be unable to participate in them, and therefore may have limited knowledge about these domains. Due to this, it is hypothesized that 4- and 5-year-old children would choose to trust the physically abled and non-obese adult rather than the physically disabled or obese adult when conflicting, domain-specific information was presented. 
Study 1 also examined children's trust of the physically disabled or obese in domaingeneral scenarios, which were scenarios about general information (e.g. animals or the alphabet) and were unrelated to the individual's physical disability. Based on the literature presented on the mixed and negative attitudes toward the physically disabled and obese, it is hypothesized that children would generally view these individuals negatively in Study 1 . This in turn would lead them to trust their domain-general testimony less, and endorse the testimony of the physically abled and non-obese individuals more often.

Since children are hypothesized to positively favour the physically abled and non-obese adult in Study 1 (in both domains), Study 2 will further examine the robustness of this potential bias, by pitting it against the informant's past history of reliability. 


\section{Study 1}

\section{Method}

Participants. The final sample included 40 children, 20 in each group of 4-year-olds ( $M$ $=52.3$ months, age range: $48.4-56.0$ months $)$ and 5-year-olds ( $M=64.1$ months, age range: $60.2-69.7$ months). There were an equal number of males and females in each age group. The sample consisted of 25 Caucasian children, 6 Asian/Pacific Islander, 3 African American, 3 Mixed, 1 Latin American, and 2 unidentifiable. One additional child was tested but removed from the final sample due to inattentiveness. Inattentiveness was defined as the child not focusing on the test stimuli, constantly getting up from the testing session and being distracted by other stimuli unrelated to the experiment (e.g. a picture on the wall). All participants were recruited using Ryerson's Infant and Child Database and at the Ontario Science Center.

Materials and stimuli. The test materials included 8 pictures of physically abled and non-obese adults (4 male, 4 female), and each was paired with a picture of a physically different adult (4 male, 4 female; two in a wheelchair, two missing both arms, and four obese). An image depicting the topic of the testimony was visually presented before each piece of testimony was provided (i.e., topic images). Furthermore, in addition to an audio recording, the content of each individual's testimony was also visually presented for the child underneath the informant's picture (i.e., content pictures). The pictures of the adult informants were taken (and edited) by the researcher. The content pictures and the topic images were obtained from online resources. The participant's parents/guardians were also given a demographics questionnaire to complete about the child. These included general questions such as the child's age and ethnicity, as well as more specific questions regarding if the child had been exposed to obese or physically disabled 
individuals and the nature of this exposure, such as who the person was (e.g., relative, friend) and how often they interacted with that person.

The stimuli consisted of 18 slides that were presented in a PowerPoint presentation on a laptop with speakers. Apart from the introduction and closing slides, each trial consisted of a slide depicting an image related to the testimony (topic image), followed by a slide containing an image of both informants, their audio testimony and two small pictures (content images) underneath each informant which visually depicted their testimony (see Figure 1 for trial examples). For example, in the "physically abled and non-obese versus physically disabled (wheelchair)" trial, the topic of the domain specific testimony was skiing. First the child was presented with an image of a pair of skis, followed by a slide showing a physically disabled individual in a wheelchair on one side, and a physically abled and non-obese individual on the other side. Each informant then presented testimony through an audio clip about a skiing trick called "the Daffy". Additionally, the testimony that described two different ski tricks was also visually presented underneath each informant's picture. 
- Figure 1. Sample stimuli in Study 1
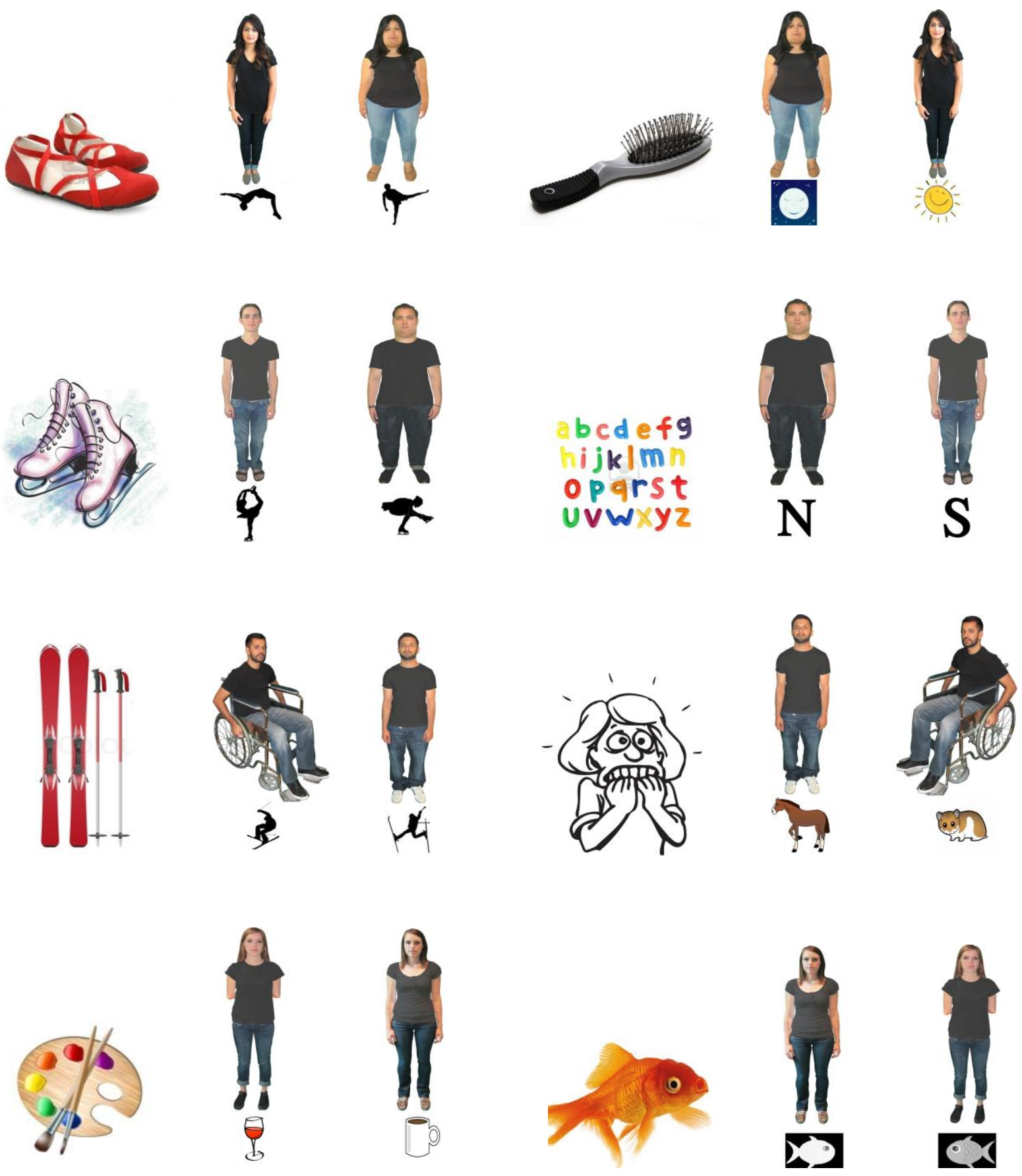

Figure 1. Stimuli for Study 1. Domain-specific trials are presented in the left column and domain-general trials are presented in the right column. Each trial consists of the topic image being presented first (left), followed by the testimony slide with content images. 
For all trials, each slide contained a picture depicting an informant that was physically abled and non-obese on one side, and an informant that was physically different (disabled or obese) on the other side. The order of the presentation of each individual was counterbalanced between slides.

Eight young adults were photographed to be informants for each trial, half for each gender. In each pair, both genders were wearing matching clothes and were matched in terms of skin colour, hair colour, and race. Each speaker's testimony was also recorded as an audio clip and was played for the child. Each audio clip was reviewed by a research team to ensure that each pair of speakers were equally confident in their claims.

Design and procedure. The study employed a 2 (age) x 2 (domain) x 2 (trial type) mixed design, with age as the between-subjects factor and domain and trial type as the within-subjects factor. At each age, each child received 4 domain-specific and 4 domain-general trials, with 2 disabled and 2 obese trials in each domain.

The study always took place in a quiet room and children were seated on a chair in front of a laptop computer. With parental consent, a video camera recorded the child's responses throughout the study.

The procedure consisted of three phases: introduction, test, and interview. In the introduction phase before beginning the PowerPoint presentation, children were told, "today were are going to learn some new things from different people, let's begin!"

Next, the test phase began and consisted of eight trials, four with male informants and four with female informants, which assessed whom children chose to trust when two adults provided conflicting testimony that was either domain-specific or domain-general. When presented with the first slide depicting an image related to the testimony, the child was asked to 
label the object presented. For example, an image of a pair of skis was presented and the child was asked, "do you know what this is?" Once the skis were correctly identified (by the child or experimenter), the experimenter asked the child a question related to the image presented. For example in the skiing trial, the child was asked, "do you know how to do the skiing move called the Daffy?" Once the child responded, the experimenter introduced the next slide depicting the two informants (e.g., one physically abled and non-obese and one physically disabled). The child was then told, "one of them knows better, let's listen to what they say." Then the audio clip of each informant's testimony was played for the child and was verbally repeated by the experimenter. For example, after the audio clips were played the experimenter stated, "He (point to the individual on left) said that you jump and turn in the air, like this (point to picture depicting action) and he (point to the individual on right) said that you do a split in the air, like this (point to picture depicting action). How do you think you do the Daffy, like this (point to content picture) like he said (point to left informant) or like this (point to content picture) like he said (point to right informant)?" After the child provided a clear response, the procedure was repeated in the next trial.

In the interview phase, children were asked their reasoning for choosing to trust the individual they selected on four trials, two domain-specific (obese male, physically disabled/wheelchair) and two domain-general (obese female, physically disabled/missing arms) . For each trial, they were asked, "Why did you choose him/her instead of him/her (pointing ...)?" If children did not answer, the prompt "Why did you think he/she knew better?" was given.

All children's responses were coded by the researcher during the testing session. A trained undergraduate research assistant performed reliability coding on a randomly selected $50 \%$ of the sample, and achieved $100 \%$ agreement with the initial responses 


\section{Results}

Preliminary analyses showed that there was no significant gender effect in this study and in the subsequent study. Therefore, this factor was excluded in the main analyses reported below. Children's choice on each trial was coded by assigning a value of 0 if the child chose the physically disabled/obese individual and a value of 1 if the child chose the physically abled and non-obese individual. The choice scores were summed up and divided by the number of trials to compose the dependent variable. See Table 1 for children's mean proportion of choosing the physically abled and non-obese informant in Study 1 (by domain and trial type).

The analyses consisted of four components. The first set of analyses consisted of three ANOVAs looking at the effects of domain and trial type. The second set of analyses consisted of a series of $t$-tests comparing children's responses to chance. The third set of analyses observed children's exposure to physically disabled and obese individuals in relation to their responses on obese and disabled trials. Lastly, children's responses to the interview questions were examined to determine if a relationship existed between their responses and their trust of physically disabled or obese individuals.

Children's testimony endorsement by domain and trial type. First, a mixed-design ANOVA with age (4 vs. 5) as the between-subjects factor and domain (DS total vs. DG total) as the within-subjects factor was conducted. The analysis revealed that there was no significant main effect of age, indicating that 4 - and 5-year-old children were responding similarly, $F(1,38)$ $=.053, p=.819$. The main effect of domain was also non-significant, which showed that children were responding on both DS and DG trials in the same way, $F(1,38)=.340, p=.563$. No significant interaction was found between age and domain, indicating that the responses to different domains did not vary with age, $F(1,38)=2.415, p=.128$. 
Next, two mixed-design ANOVAs were conducted to examine if a difference existed in trial type within domain-specific scenarios and within domain-general scenarios. Age served as the between-subjects factor and trial type (DS-disabled and DS-obese, or DG-disabled and DGobese) as the within-subjects factor.

The analyses revealed no significant main effect of age, which indicated that both 4- and 5-year-olds were responding similarly to DS-disabled and DS-obese trials, $F(1,36)=1.697, p=$ .201 , and to DG-disabled and DG-obese trials, $F(1,36)=1.142, p=.292$. Additionally, there was no main effect of trial type in both analyses, which illustrates that responses to DS-disabled and DS-obese trials and to DG-disabled and DG-obese trials were comparable, $F(1,36)=.196$, $p=.660$, and $F(1,36)=1.017, p=.319$, respectively. There was no significant interaction between age and trial type for DS scenarios, $F(1,36)=1.069, p=.308$, or for DG scenarios, $F$ $(1,36)=1.682, p=.202$. This indicates that responses to trial type did not vary as a function of age.

Children's testimony endorsement in comparison to chance expectations. The second set of analyses consisted of a series of $t$-tests comparing performance to chance expectations (see Table 1). The DS and DG trials were each calculated as a total out of 4 , and divided by the number of trials to determine the mean proportion. The value of chance was calculated as 0.5 . The first $t$-test was to determine if there was a significant difference in children's responding to DS and DG trials in comparison to chance. The analysis revealed that children favoured the testimony of the physically abled and non-obese individual at a level significantly above chance when learning both domain-specific $(59 \%)$ and domain-general knowledge $(63 \%), t(39)=$ $2.152, p=.038, r=.33$ and $t(39)=3.201, \mathrm{p}=.003, r=.46$, respectively. 


\section{Table 1}

Mean proportion of trials on which children chose the physically abled and non-obese informant in Study 1 (by domain, and trial type; SD in parentheses)

Trial Type

N Obese Trials $\quad$ Disabled Trials Total

40

$\begin{array}{llll}\text { Domain-specific } & .61(.383) & .58(.384) & .59(.275)^{*} \\ \text { Domain-general } & .68(.416)^{*} & .59(.337) & .63(.259)^{* *} \\ \text { Total } & .64(.270)^{* *} & .58(.229)^{*} & \end{array}$

** If $\mathrm{p}<.01 ; *$ if $\mathrm{p}<.05$

Four one-sample $t$-tests were conducted to examine if there was a significant difference in children's responding to DS-disabled, DS-obese, DG-disabled, and DG-obese trials in comparison to chance. The analyses revealed that in DS-obese trials, children were choosing the physically abled and non-obese individuals more often than chance $(61 \%)$, although this finding was approaching significance, $t(39)=1.854, p=.071, r=.28$. Additionally, the analyses revealed that in DG-obese trials, children were significantly choosing the physically abled and non-obese individuals more often than chance $(68 \%), t(39)=2.655, p=.011, r=.39$. Children responded similarly to chance when choosing the physically abled and non-obese individual on DS-disabled $(58 \%)$ and DG-disabled trials $(59 \%), t(39)=1.233, p=.225$ and $t(39)=1.639, p=$ .109 , respectively.

A one-sample $t$-test was also conducted to examine if there was a significant difference in children's responding to overall physical condition (obese or disabled) in comparison to chance. The total for the obese and disabled trials were each calculated out of a value of 4 and divided by 
the number of trials to determine the mean proportion. Chance was calculated as a value of 0.5.The $t$-test revealed that on obese trials overall, children were more likely to choose the physically abled and non-obese individual at a rate significantly higher than chance (64\%), $t$ (39) $=3.357, p=.002, r=.47$. Additionally, on physically disabled trials overall, children were also more likely to choose the physically abled and non-obese individual at a rate significantly higher than chance $(58 \%), t(39)=2.242, p=.031, r=.34$.

\section{The impact of prior exposure to obese and disabled individuals on testimony}

endorsement. The third set of analyses examined if children's exposure to physically disabled or obese others impacted their testimony endorsement. Based on parental report as described earlier, children were categorized into two groups (with or without exposure) for each physical condition (obese, disabled). Children whose parents were unsure of their exposure or did not respond to the questions were excluded from the analyses.

The data from 30 children and their exposure to obese individuals were included for the first analysis. A mixed-design ANOVA was conducted with exposure to obese individuals as the between-subjects factor and domain (DS_obese trials vs. DG_obese trials) as the within-subjects factor. This was to examine if exposure to obese individuals influenced how children responded on all four normal-vs.-obese trials. The results revealed that there was no significant main effect of exposure, $F(1,28)=2.530, p=.123$, suggesting that children with or without exposure to obese individuals did not significantly differ in their testimony endorsement. The main effect of domain was also not significant, $F(1,28)=.005, p=.944$, suggesting that children were responding to domain-specific and domain-general trials in the same way. However, there was a significant interaction between exposure and domain, $F(1,28)=4.194, p=.050$, partial $\eta^{2}=$ .13. This indicates that responses to obese trials varied as a function of exposure. 
To examine this interaction further, an independent-samples $t$-test was conducted.

Children with or without exposure to obese individuals were compared in how they responded on the DS_obese trials as well as on the DG_obese trials. The results revealed that on the DS-obese trials, there was no significant difference between the two groups of children, $t(28)=-.313, p=$ .20. On these trials, children with exposure chose the non-obese individuals $67 \%$ of the time, and those without exposure chose them $63 \%$ of the time.

However, on the DG_obese trials, there was a significant difference between the two groups of children, $t(26.86)=2.749, p=.011, r=.47$. Children with exposure chose the nonobese individual $47 \%$ of the time, and those without exposure chose them $83 \%$ of the time.

In other words, when learning domain-general knowledge, children with exposure to obese individuals chose to endorse their testimony more often than those without.

For the next analysis, the data from 32 children and their exposure to disabled individuals were used. A mixed-design ANOVA was conducted with exposure to disabled individuals as the between-subjects factor and domain (DS_disabled vs. DG_disabled trials) as the within-subjects factor. This was to examine if exposure to disabled individuals influenced children's responses on normal-vs.-disabled trials. The results showed no significant main effect of exposure, $F$ (1, $30)=.003, p=.959$, suggesting that children with or without exposure to disabled individuals did not differ significantly differ in in their performance. There was also no significant main effect of domain, $F(1,30)=.014, p=.907$, suggesting that children were responding similarly on both domain-specific and domain-general trials. On DS_disabled trials, children without exposure chose the physically abled individual $59 \%$ of the time, and children with exposure chose them 55\% of the time. On DG_disabled trials, children without exposure chose the 
physically abled individual $57 \%$ of the time, and those with exposure chose them $60 \%$ of the time.

Additionally, there was no significant interaction between exposure and domain, $F(1$, $30)=.100, p=.755$. This indicates that responses on normal-vs.-disabled trials did not vary as a function of children's exposure to disabled individuals.

Children's justifications for their testimony endorsement. The interview questions were implemented to examine children's reasoning for choosing to trust the individual they selected on four trials, two domain-specific and two domain-general.

Children's responses were coded into six categories and the frequency of the responses were recorded and categorized by age, domain and trial type (see Table 2). Overall, children's reasoning for choosing different speakers did not show a relation to physical disability/obesity. Only one child gave an explanation that may have related to obesity, "I don't know, because she's bigger." Generally, 4-year-old children's responses indicated that they were mainly guessing or had no reason for choosing one speaker over the other. They also mainly gave superficial responses (judgement about speaker) such as "because (s)he is right, because s(he) said so" when asked for their reasoning for endorsing a speaker's testimony. Some children also gave responses that were in direct relation to the testimony facts themselves. For example, when asked which informant was correct when explaining the skating move called the "Biellman spin," the child responded "'because he skates on one leg and you put your other leg up."

When looking at the frequency of 5-year-old's responses, the same patterns are seen. Overall, none of the children indicated that physical disability/obesity of the speaker played a role in their testimony endorsement. However, at this age an increase in the frequency of 5-yearold's responses relating to the testimony facts was seen. For example, when asked if hippophobia 
was the fear of horses or hamsters, one child explained that it was horses because "the horses gallop and you can fall."

Table 2

Children's Responses to the Interview Questions in Study 1

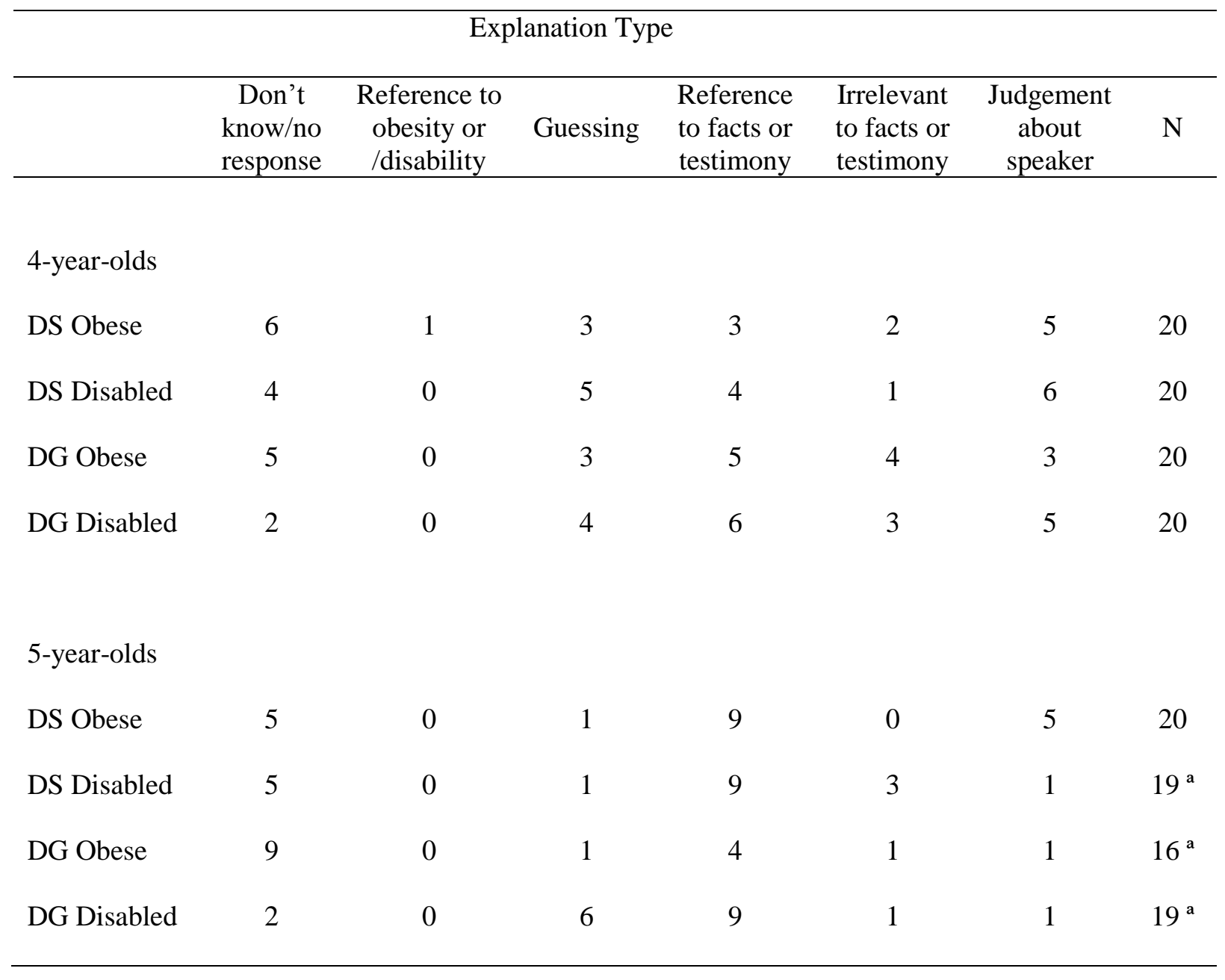

Note: This table illustrates the frequency of different types of responses that 4- and 5-year-old children expressed during their interview. These answers are their justification for endorsing the testimony of the speaker they had chosen.

${ }^{a}$ Some children were not asked some interview questions due to experimenter error.

\section{Discussion}


The results of this study suggest that a speaker's physical condition did have an impact on children's learning from others. This is indicated by their preference for physically abled and non-obese individuals when evaluating their testimony about novel information. The responses of 4- and 5-year-old (male and female) children were alike in that they responded to both domains in a similar way. When comparing performance to chance, children were shown to favour the testimony of the physically abled and non-obese individual in both domains. Also, 4and 5-year-old children responded similarly to all trial types (DS-Obese, DS-Disabled, DGObese, DG-Disabled). When children's responses were compared to chance across the four trial types, children were seen to favour the physically abled and non-obese individual over the obese individuals across both DS and DG scenarios. However, when responding to physically abled and non-obese versus physically disabled speakers, children did not show a significant preference. When physical condition (obese, physically disabled) was assessed overall, children were also found to significantly favour the physically abled and non-obese individuals over the obese and disabled individuals in comparison to chance. This indicated that when assessed entirely, children preferred to trust the physically abled and non-obese individual across all trials.

When looking at the influence of exposure to obese individuals on children's responses to the four obese trials, the analyses showed that children with and without exposure preferred to endorse the testimony of physically abled and non-obese individuals across both DS trials. However, this was not the case for DG obese trials, where children with the exposure chose the obese individual's testimony more often than those without the exposure.

When looking at the influence of exposure to disabled individuals on disabled trial responses, no significant difference in responding was found between children with or without exposure. Additionally, children's responses to interview questions did not provide an in-depth 
reasoning for their informant selection. The majority of children's responses were superficial and indicated that they were just guessing, did not know the answer or they attempted to relate it to the testimony itself, not the informant. This finding will be discussed in detail in General Discussion.

The strength of this preference for physically abled and non-obese individuals and the findings above generally agree with the literature on children's mixed attitudes toward physically disabled individuals (Dyson, 2005; Nowicki \& Sandieson, 2002; Spillers, 1982) and negative attitudes toward obese individuals (Cramer \& Steinwert, 1998; Kraig \& Keel, 2001; Wei \& Di Santo, 2011; Tiggeman \& Anesbury, 2000; Tillman et al., 2007; Turnbull et al., 2000). Given children's overall preference for the testimony of physically abled and non-obese individuals, in Study 2 we further examined the strength of this bias, by pitting physical condition against past reliability. We chose to include only the four DS trials from Study 1 because there was no overall domain effect on children's responses. Also, the DS trials were more directly related to the informant's physical condition and more relevant to the research question at hand.

More specifically, in Study 2 we examined if children continued to endorse the testimony of physically abled and non-obese individuals, even when they had been shown to be previously unreliable. Previous research on accuracy shows that preschoolers trust informants that have previously been accurate in their testimony (e.g., Clement et al., 2004; Einava \& Robinson, 2010; Jaswal \& Neely, 2006; Koenig \& Harris, 2005; Koenig et al., 2004; Liu et al., 2013; Scofield et al., 2013). A study by Ma and Ganea (2010) also showed that with a single prior exposure to the adult as an unreliable source of information, 3- and 4-year-olds became skeptical of the adult's false testimony and relied on their own observations to find an object. 
Based on the findings above, we hypothesized that the positive bias toward physically abled and non-obese individuals would disappear when children were exposed to a single instance of their unreliability. Therefore, children would place more trust in the testimony of physically disabled and obese individuals who were shown to be previously accurate in their testimony. 


\section{Study 2}

\section{Method}

Participants. The final sample included 40 children, 20 four-year-olds $(M=53.4$ months, age range: $48.1-59.1$ months) and 20 five-year-olds ( $M=66.1$ months, age range: 60.4 - 71.2 months). The sample consisted of 20 Caucasian children, 9 Asian/Pacific Islander, 5 Mixed, 2 African American, and 3 unidentifiable. An additional seven children were tested but excluded due to incompleteness, not meeting the age criteria and for not passing the history phase of the study. All participants were recruited using Ryerson's Infant and Child Database and at the Ontario Science Center.

Materials and stimuli. The test materials included 10 PowerPoint slides from Study 1 (the introduction slide, the eight slides for the four domain-specific test trials, and the closing slide). In addition, four history slides were used, one for each test trial. On each history slide, the two speakers provided conflicting testimony about the name of a familiar object (e.g., a ball). The physically disabled or obese individual was always correct in their testimony (e.g., "this is a ball") whereas the physically abled and non-obese individual was always incorrect (e.g., "this is a book") (for an example see Figure 2). 
- Figure 2. Sample stimuli in Study 2
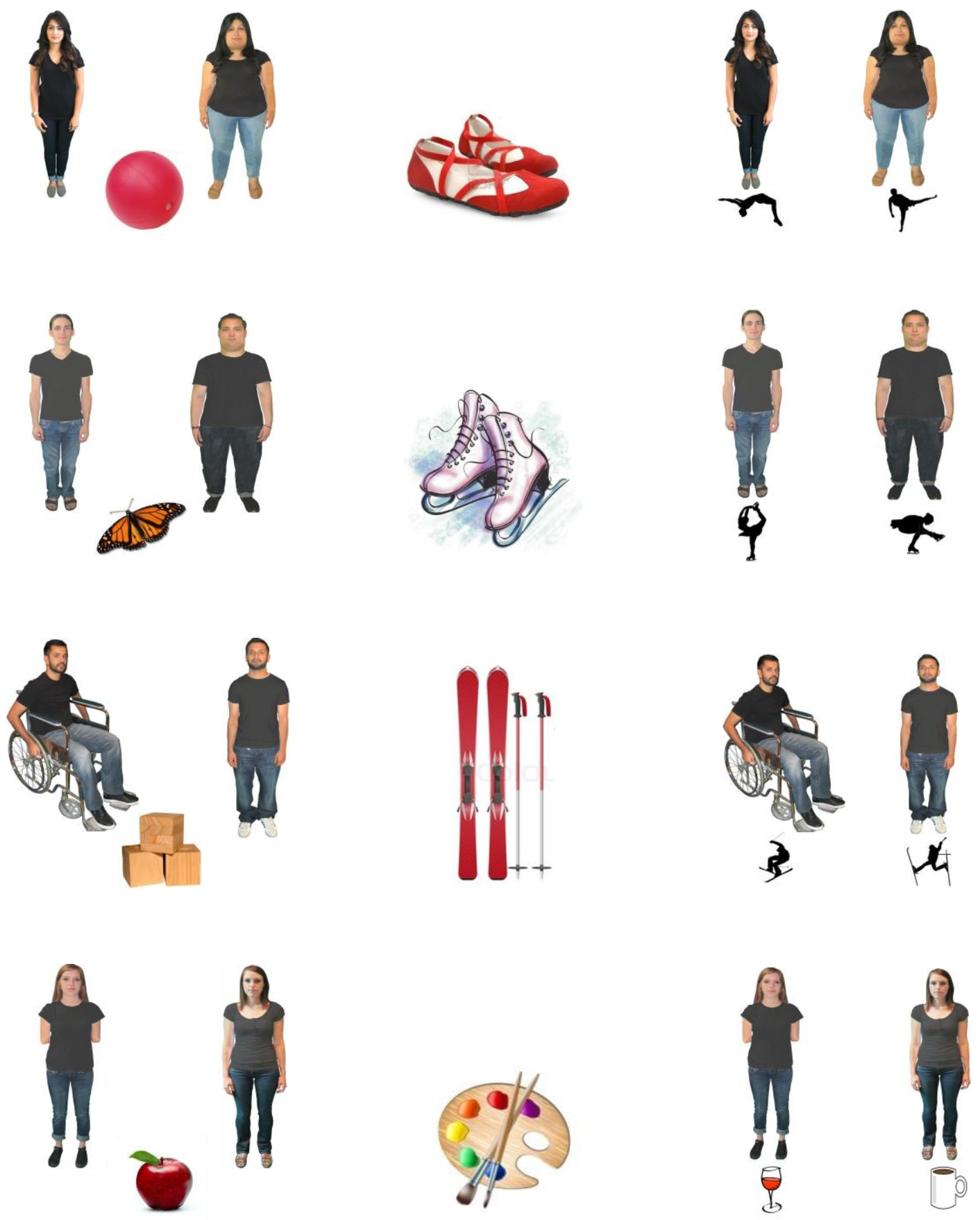

Figure 2. Stimuli for Study 2. For each trial, the child is presented with the history slide first (left), followed by the topic image (middle), and lastly the testimony slide with content images (right) is presented. 
Design and procedure. The study employed a 2 (age) x 2 (trial type) mixed design, with age as the between-subjects factor and trial type as the within-subjects factor. At each age, each child received 2 obese and 2 disabled trials.

After children were introduced to the task as in Study 1, the four test trials began. Each trial consisted of two phases: history and test. In the history phase, the physically disabled or obese informant labeled a familiar object correctly whereas the physically abled and non-obese informant labeled it incorrectly. This was to show children that the physically abled and nonobese adult's testimony of the object label was unreliable (and this is the case in all 4 history phases). First the child was asked to label the picture of the familiar object presented. For example, an image of a ball was presented and the child was asked, "do you know what this is?" Once the ball was correctly identified, the experimenter pointed to the informants and told the child, "let's listen to what they call it, one of them knows better." Then, the audio clip of each informant's testimony was played for the child and was verbally repeated by the experimenter. For example, after the audio clips were played the experimenter stated, "she (point to left character) said that this (point to ball) is called a book, and she (point to right character) said that this is called a ball. Who do you think is right?" After the child responded, the same procedure was used in the following history phases.

Next, the test phase procedure mimicked the domain-specific trials that were presented in study 1 which included a topic image followed by the domain-specific testimony slide.

All children's responses were coded by the researcher during the testing session. A trained undergraduate research assistant performed reliability coding on a randomly selected $50 \%$ of the sample, and achieved $100 \%$ agreement with the initial responses. 


\section{Results and discussion}

Children's testimony endorsement by trial type. Before the analyses was conducted, children's choice on each trial was coded by assigning a value of 0 if the child chose the physically disabled/obese individual and a value of 1 if the child chose the physically abled and non-obese individual. The choice scores were summed up and divided by the number of trials to compose the dependent variable. See Table 3 for children's mean proportion of choosing the physically abled and non-obese informant in Study 2 (by trial type).

A mixed-design ANOVA with age (4 vs. 5) as a between-subjects factor and trial type (Obese total vs. Disabled total) as a within-subjects factor was conducted to examine if children responded differently in obese and disabled trials. The analysis revealed that there was no significant main effect of age, indicating that 4- and 5-year-old children were responding similarly, $F(1,38)=2.267, p=.140$. The main effect of trial type was also non-significant, which showed that children were responding to trials with both physical conditions (Obese and Disabled) in the same way, $F(1,38)=.529, p=.472$. No interaction effect was found between age and trial type, indicating that the responses to different physical condition trials did not vary with age, $F(1,38)=.235, p=.631$.

\section{Children's testimony endorsement in comparison to chance expectations. Next, a}

series of $t$-tests comparing performance to chance were conducted. The first $t$-test was to determine if there was a significant difference in children's responding to Obese and Disabled trials in comparison to chance. The Obese and Disabled trials were each calculated as a mean proportion, and the value of chance was calculated as 0.5 . The analysis revealed that children did not favour the testimony of the physically abled and non-obese individual in obese trials (41\%), $t$ $(39)=-1.312, p=.197$, or in the disabled trials $(49 \%), t(39)=-.190, p=.850$. This showed that 
children were choosing to trust a speaker's testimony at a level comparable to chance. See Table 2 for mean proportion of trials on which children chose the physically abled and non-obese informant in Study 2

A one-sample $t$-test was also conducted to examine if there was a significant difference in children's responding to the overall test trials in comparison to chance. The $t$-test revealed a nonsignificant result, $t(39)=-1.185, p=.243$, which indicated that out of the 4 trials presented children favoured the physically abled and non-obese individual only $45 \%$ of time, and chose according to chance.

\section{Table 3}

Mean proportion of trials on which children chose the physically abled and non-obese informant in Study 2 (by trial type; SD in parentheses)

\begin{tabular}{llll}
\hline \multicolumn{4}{c}{ Trial Type } \\
\hline $\mathrm{N}$ & Obese Trials & Disabled Trials & Total \\
\hline 40 & $.41(.421)$ & $.49(.415)$ & $.45(.266)$ \\
\hline
\end{tabular}

\section{The impact of prior exposure to obese and disabled individuals on testimony}

endorsement. The following analyses are similar to Study 1 in that they also examine the influence that exposure to obese/physically disabled individuals may have on children's responses. The data for 30 children and their exposure to obese individuals were included for the first analyses. A one-way ANOVA was conducted with exposure to obese individuals (with or without exposure) as a between-subjects factor and Obese Total as a within-subjects factor. This was to examine if exposure to obese individuals influenced how children responded to both obese trials. The analyses revealed that there was no significant difference, $F(1,28)=.132, p=$ 
.719 , in how children with or without exposure responded to obese trials overall. Children with exposure choses the non-obese individual $46 \%$ of the time, and children without exposure chose them $41 \%$ of the time.

Next, the data for 31 children and their exposure to physically disabled individuals was included. A one-way ANOVA was conducted to examine the relationship between exposure to disabled individuals (without or without exposure) and responses to disabled trials (Disabled Total). The analyses showed that there was also no significant difference, $F(1,29)=3.720, p=$ .064 , in how children with or without exposure responded to disabled trials overall. Children with exposure chose the physically abled individual $63 \%$ of the time, and children without exposure chose them $34 \%$ of the time.

Discussion. The results of this study suggest that an informant's accuracy could potentially influence children's willingness to trust physically disabled and obese individuals. This is indicated by children choosing to trust the testimony of previously reliable physically disabled and obese individuals more often (in comparison to Study 1), when physically abled and non-obese individuals are shown to be unreliable.

All children were aware and able to indicate that the obese or physically disabled individual was correct in all history phases. The responses of 4- and 5-year-old children showed that they responded similarly to obese and disabled trials and their responses did not vary depending on the informant's physical condition (obese or physically disabled). Also, children were choosing whom to trust at a rate similar to chance. Additionally, when exposure to obese and disabled individuals was considered, children with or without exposure did not differ in their responses. 
Overall, the results indicate that children do not significantly favour the testimony of one individual over another. Even when the physically abled and non-obese individual was shown to be previously inaccurate, children still chose at random. In line with previous findings on children's negative perceptions of physically disabled or obese individuals, children place less trust in their testimony (as shown in Study 1), however, Study 2 shows that past reliability might cancel out this effect. 


\section{General Discussion}

The present study was conducted to examine children's preference for choosing physically abled and non-obese vs. physically disabled or obese individuals when providing novel testimony. For Study 1, we hypothesized that 4- and 5-year-old children would exhibit a preference for endorsing the testimony of the physically abled and non-obese individual when both domain specific and domain general information was presented. After children showed a positive bias for the physically abled and non-obese individual during these trials in Study 1, we investigated this bias further by examining the role of unreliability and its effect on physical condition and testimony endorsement. Each of the findings is discussed in more detail below.

The findings showed that there was no effect of gender or age in both studies. The lack of an age and gender effect is consistent with previous social perception literature (Favazza \& Odom, 1997; Lerner \& Gellert, 1969; Lerner \& Korn, 1972) in that these groups have shown similar attitudes toward physically disabled and obese individuals.

Study 1 also showed no main effect of domain, which indicated that children were responding to domain-specific and domain-general trials similarly. This is inconsistent with what we would expect based on the cognitive division of labour theory, in which children would exhibit a preference for the physically abled and non-obese individual in domain-specific trials but not in domain-general trials. This is because children may see the physically abled and nonobese individual as encompassing more knowledge about domain-specific information due to their lack of a disability. Previous research has shown children perceiving this bias of knowledge in areas such as gender (Ma and Woolley, 2013) and occupation (Lutz and Keil, 2002). Instead of showing a difference in responding between both domains, Study 1 showed children responding to both domains similarly. In comparison to chance, children were shown to endorse 
the physically abled and non-obese individuals testimony in domain-specific and domain-general scenarios and in obese and disabled trials overall. Children also favoured the physically abled and non-obese individual more in the obese trials when separated by domain.

The "halo effect" could be a potential explanation for why children favoured the physically abled and non-obese individual across domains. Previous literature has labelled "halo effects" as children assuming that if someone was an expert in one domain, they would extend this same knowledge and expertise to other domains (Koenig \& Jaswal, 2011). Children and adults have also been found to assume that if an individual possesses one good trait, they will possess other positive traits. For example, Cain, Heyman, and Walker (1997) showed that 4- and 5-year-old children believed that a nice child would also be smarter and more athletic than a mean child would, even though the goodness of a person is not impacted by their intelligence or athletic ability. Additionally, research shows that people tend to ascribe positive qualities to individuals that are physically attractive (Feingold, 1992). A study by Wilson and Eckel (2006) found that physical attractiveness played a role in people's trust of strangers. Their results showed that attractive individuals were viewed and believed to be more trustworthy than their unattractive counterparts. Due to the influence of physical attractiveness on trust, children may have potentially viewed the physically abled and non-obese adults more positively, which led them to attribute more positive qualities to them. This may have led them to trust their testimony more, and neglect the testimony of the physically disabled or obese individuals across all trials.

One could argue that the digital alteration of the images of obese informants may have caused them to appear stretched and distorted. This could have led the children to perceive the obese informants as weird and different from themselves, which would lead to their preference for the non-obese individuals. However, we do not believe that the digital alteration of the 
stimuli led the children to believe this. Children that were tested constantly spoke about the genuineness of the pictures and made various comments such as "she's chubby", "she has no arms", "he's fat". No child tested made any comments questioning the authenticity of the photographs, and we concluded that this was not an issue. Also, these pictures were presented to various colleagues and research assistants, all of whom agreed that the stimuli was appropriate and realistic for the testing procedures.

The study shows a preference for physically abled and non-obese individuals in domainspecific and domain-general scenarios (medium size effect). This is consistent with Richardson's (1983) study, where children were shown to consistently rank the physically abled and non-obese individual as more favourable than physically disabled and obese individuals. The findings above also agree with the literature presented which shows children's mixed attitudes toward physically disabled individuals (Dyson, 2005; Nowicki \& Sandieson, 2002; Spillers, 1982) and negative attitudes toward obese individuals (Cramer and Steinwert, 1998; Kraig \& Keel, 2001; Wei \& Di Santo, 2011; Tiggeman \& Anesbury, 2000; Tillman et al., 2007; Turnbull et al., 2000). These findings could potentially explain why children showed a mixed preference for choosing whom to trust in DS Disabled and DG Disabled trials. They chose similarly to chance which may indicate mixed or uncertain perceptions of physically disabled individuals at this age. However, when considering disabled trials overall, children preferred to choose the physically abled and non-obese individual at a rate higher than chance. This could be due to the fact that children prefer the physically abled and non-obese individuals overall in comparison to physically disabled individuals, as shown in previous literature (Richardson, 1983). However, their mixed attitudes may be an indication of not knowing whom is more knowledgeable in the testimony and not an indication of whom they prefer physically. 
Their later study examined children's attitudes towards the physically disabled by requiring them to rank disabled characters from most to least liked. It was found that children preferred (from most to least) the non-disabled child, child with crutches/brace, child in a wheelchair, child without a hand, child with a facial abnormality, and an obese child. Even children with a physical handicap ranked their preferences in the same way that the nonhandicapped children did (Richardson, 1983). Additionally, children favouring the physically abled and non-obese over obese individuals across both domains, may be indicative of a more solidified negative perception of obese individuals during this stage of development.

When analyzing the frequency of responses of children's interview questions, almost all responses were superficial and unsophisticated in nature. Children did not express an in-depth reason for preferring one informant over another, and did not mention physical disability/obesity, with the possible exception of one child. A reason for these underdeveloped responses may show a lack of developmental maturity. Children may not be able to express their reasoning for their choices at this age due to language and cognitive barriers. However, they may still be choosing informants based on their physical preferences, but may be unable or ashamed to indicate their reasoning. However, it is also possible that children were showing sophistication in their responses by not pointing out the informant's disability, and were trying to be politically correct and polite. A study conducted by Talwar and Lee (2002) showed that children as young as 3years-old engaged in "white lie telling", as they told an experimenter with a red mark on her nose that she looked fine just before her picture was taken. However, once the experimenter had left the room, the children expressed that she did not in fact look okay due to the mark on their nose. It is possible that children in the current study might be aware of a person's physical disability or 
obese body type, but enengage in lying in order to remain polite and avoid hurting the feelings of others.

The findings of Study 2 indicate that the effect of the positive bias toward physically abled and non-obese individuals shown in Study 1 was reduced when the physically abled and non-obese individual was shown to be previously unreliable or inaccurate before each trial. In Study 1, children chose to trust the physically abled and non-obese individual overall across trials (in comparison to chance), whereas in Study 2 they did not. Children in Study 2 chose at a rate close to chance, and overall the positive bias disappeared across all four trials. Previous research shows that preschoolers trust informants that have previously been accurate in their testimony (Clement et al., 2004; Einava \& Robinson, 2010; Jaswal \& Neely, 2006; Koenig \& Harris, 2005; Koenig et al., 2004; Liu et al., 2013; Scofield et al., 2013) and prefer to endorse the accurate individual's testimony when learning novel information (Birch et al., 2008; Rakoczy et al., 2009; Scofield \& Behrend, 2008). To be consistent with previous research on accuracy, children would have had to significantly endorse the testimony of the physically disabled and obese individuals across all trials because they were shown to be reliable in their testimony. However, children not showing this may be because they were conflicted in deciding if accuracy or physical condition was more important in testimony endorsement. Although the results did not show that accuracy completely predicted testimony endorsement, it did play a role in cancelling out the negative effect that physical condition had on testimony endorsement in Study 1.

In both studies, children's testimony endorsement did not differ as a function of their prior exposure to disabled/obese individuals. However in one case, exposure did influence children's responses to domain-general obese trials in Study 1, where children with more exposure to obese individuals, favoured their testimony more than the non-obese individual. The 
larger effect for domain-general obese trials may be due to a "block effect". In the study, all children were presented with the block of domain-specific trials first and then the block of domain-general trials. It is possible that children learned the researcher's expectations when taking the domain-specific trials first, and were more aware of what? when the domain-general trials were presented. This may have influenced their responses and increased the effect in the domain-general block of trials.

Another explanation is that children with prior exposure to obese individuals for Study 1 may have a better understanding about the limitations obese individuals may face with the novel activities in the domain-specific obese trials. This may be the reason for their preference for the non-obese individuals in these trials, but not in the domain-general trials.

A study by Favazza \& Odom (1997) provides a potential explanation for exposure not influencing children's attitudes or responses toward physically disabled/obese individuals across most trials. Their study showed that children that had high contact with individuals with disabilities showed increased levels of acceptance, whereas children in the low and no contact groups did not differ in their acceptance levels (which did not increase). In addition, the contact hypothesis theory states that under positive conditions, the best way to reduce prejudice between majority and minority group members is through interpersonal contact. If the contact is positive and occurs often in multiple contexts, this should reduce prejudice and lead to better interactions between outgroups (Allport, 1954). Most children in Studies 1 and 2 may have not had high levels of exposure and direct contact with physically disabled/obese individuals, and may have only experienced little or no contact. Since this may be the case, children in the exposure or no exposure group were very similar and the exposure may not have been enough to elicit a significant difference in responses. It is possible that if children interacted with physically 
disabled and obese individuals frequently and under positive circumstances, then their responses may change to reflect a more positive bias toward these individuals. Although these are potential explanations in how exposure could affect children's responses, the frequency and nature of exposure to physically abled and non-obese individuals and its effects on trust, is worth further examination.

The current paradigm holds a limitation in that it forces children to make a choice when two informants are placed in direct contrast with one another. It is possible that this forced choice affects whom children choose to trust, as a third option was not available to them. To address the question of children's willingness to trust the physically disabled and obese, another paradigm could be used that does not involve the direct contrast between two informants. For example, a study by Ma and Ganea (2010) had an adult place a toy in one location as the child watched, and then told the child that the toy was hidden in a different location from where they had hidden it. It was of interest to see if the child would find the hidden toy by relying on their own observations, or by trusting the conflicting testimony of the adult. This paradigm could be used to address the research questions in this paper. For example, a physically abled individual could provide testimony to the child regarding the location of an object, and see if the child chooses to trust their testimony. After the individual provides correct information a few times, they could provide one instance of unreliable testimony and see if the child continues to trust their testimony. Then, this procedure could be repeated with physically disabled individuals, as well as with obese individuals.

This study was successful in providing evidence that children as young as 4 years old prefer to trust the testimony of physically abled and non-obese individuals over physically disabled or obese individuals. However, when physically abled and non-obese individuals were 
portrayed as unreliable, this effect disappeared. This research provides a unique contribution to the literature on social evaluation and trust, because it is of the first to examine the relationship between physical disability, obesity and trust. The findings from this research are also of great importance in everyday living because the attitudes held by children will influence their behaviour toward physically different individuals (Richardson, 1970). By examining how children trust physically different individuals, we will be better able to help change their attitudes and behaviours towards these individuals at an early age, which will subsequently create positive social interactions. Future research should examine other factors to provide more insight into the role of informant physical characteristics in testimony endorsement. For example, many other physical disabilities can be examined such as facial disfigurements, leg amputations and the use of crutches. Since the effect was strongest toward obese individuals, it would be of interest to examine this population more closely. Studies could be conducted that observe how obese children trust the testimony of obese vs physically abled and non-obese informants. This would be of interest because it would determine if the negative perceptions of obese informants are also endorsed by obese children and not only by physically abled and non-obese children. Therefore, by examining more types of physical disabilities and obesity, more knowledge can be gained about children's attitudes and perceptions towards these individuals. This will allow us to achieve more insight into this area to inform important educational interventions. 


\section{References}

Allport, G. W. (1954). The nature of prejudice. Cambridge, MA: Perseus Books

Birbeck, D., \& Drummond, M. (2005). Interviewing, and listening to the voices of, very young children on body image and perceptions of self. Early Child Development and Care, 175(6), 579-596. doi: 10.1080/03004430500131379

Birch, S. A. J., Vauthier, S. A., \& Bloom, P. (2008). Three- and four-year-olds spontaneously use others' past performance to guide their learning. Cognition, 107(3), 1018-1034. doi: 10.1016/j.cognition.2007.12.008

Burton, S., \& Mitchell, P. (2003). Judging who knows best about yourself: Developmental change in citing the self across middle childhood. Child Development, 74(2), 426-443. doi: $10.1111 / 1467-8624.7402007$

Bussey, K., \& Bandura, A. (1984). Influence of gender constancy and social power on sex-linked modeling. Journal of Personality and Social Psychology, 47(6), 1292-1302. doi: $10.1037 / 0022-3514.47 .6 .1292$

Cain, K. M., Heyman, G. D., \& Walker, M. E. (1997). Preschoolers' ability to make dispositional predictions within and across domains. Social Development, 6(1), 53-75. doi: $10.1111 / 1467-9507.00026$

Chudek, M., Heller, S., Birch, S., \& Henrich, J. (2012). Prestige-biased cultural learning: Bystander's differential attention to potential models influences children's learning. Evolution and Human Behavior, 33(1), 46-56. doi: 10.1016/j.evolhumbehav.2011.05.005

Clément, F., Koenig, M., \& Harris, P. (2004). The ontogenesis of trust. Mind \& Language, 19(4), 360-379. doi: 10.1111/j.0268-1064.2004.00263.x 
Corriveau, K., \& Harris, P. L. (2009). Preschoolers continue to trust a more accurate informant 1 week after exposure to accuracy information. Developmental Science, 12(1), 188-193. doi: $10.1111 / j .1467-7687.2008 .00763 . x$

Cramer, P., \& Steinwert, T. (1998). Thin is good, fat is bad: How early does it begin? Journal of Applied Developmental Psychology, 19(3), 429-451. doi: 10.1016/S0193-3973(99)800495

Dawkins, R. (1995). Putting away childish things. The Skeptical Inquirer, 19(1), 31.

Dyson, L. L. (2005). Kindergarten children's understanding of and attitudes toward people with disabilities. Topics in Early Childhood Special Education, 25(2), 95-105. doi: $10.1177 / 02711214050250020601$

Einav, S., \& Robinson, E. J. (2010). Children's sensitivity to error magnitude when evaluating informants. Cognitive Development, 25(3), 218-232. doi: 10.1016/j.cogdev.2010.04.002

Fabes, R. A., Shepard, S. A., Guthrie, I. K., \& Martin, C. L. (1997). Roles of temperamental arousal and gender-segregated play in young children's social adjustment. Developmental Psychology, 33(4), 693-702. doi: 10.1037/0012-1649.33.4.693

Favazza, P. C., \& Odom, S. L. (1997). Promoting positive attitudes of kindergarten-age children toward people with disabilities. Exceptional Children, 63(3), 405.

Feingold, A. (1992). Good-looking people are not what we think. Psychological Bulletin, 111(2), 304-341. doi:10.1037/0033-2909.111.2.304

Fusaro, M., \& Harris, P. L. (2008). Children assess informant reliability using bystanders' nonverbal cues. Developmental Science, 11(5), 771-777. doi: 10.1111/j.14677687.2008.00728.x 
Gilbert, D. T. (1991). How mental systems believe. American Psychologist, 46(2), 107-119. doi: 10.1037/0003-066X.46.2.107

Gopnik, A., \& Graf, P. (1988). Knowing how you know: Young children's ability to identify and remember the sources of their beliefs. Child Development, 59(5), 1366-1371. doi: 10.1111/j.1467-8624.1988.tb01505.x

Grace, D. M., David, B. J., \& Ryan, M. K. (2008). Investigating preschoolers' categorical thinking about gender through imitation, attention, and the use of self-categories. Child Development, 79(6), 1928-1941. doi: 10.1111/j.1467-8624.2008.01234.x

Harper, D. C. (1997). Children's attitudes toward physical disability in nepal: A field study. Journal of Cross-Cultural Psychology, 28(6), 710-729. doi: 10.1177/0022022197286004

Harris, P. L. (2002). Checking our sources: The origins of trust in testimony. Studies in History and Philosophy of Science, 33(2), 315-333. doi: 10.1016/S0039-3681(02)00007-9

Harris, P. L. (2007). Trust. Developmental Science, 10(1), 135-138. doi: 10.1111/j.14677687.2007.00575.x

Jaswal, V. K., \& Neely, L. A. (2006). Adults don't always know best: Preschoolers use past reliability over age when learning new words. Psychological Science, 17(9), 757-758. doi: 10.1111/j.1467-9280.2006.01778.x

Kinzler, K. D., Corriveau, K. H., \& Harris, P. L. (2011). Children's selective trust in nativeaccented speakers. Developmental Science, 14(1), 106-111. doi: 10.1111/j.14677687.2010.00965.x

Koenig, M. A., \& Harris, P. L. (2005). Preschoolers mistrust ignorant and inaccurate speakers. Child Development, 76(6), 1261-1277. doi: 10.1111/j.1467-8624.2005.00849.x 
Koenig, M. A., Clément, F., \& Harris, P. L. (2004). Trust in testimony: Children's use of true and false statements. Psychological Science, 15(10), 694-698. doi: 10.1111/j.09567976.2004.00742.x

Koenig, M. A., \& Jaswal, V. K. (2011). Characterizing children's expectations about expertise and incompetence: Halo or pitchfork effects? Child Development, 82(5), 1634-1647. doi: 10.1111/j.1467-8624.2011.01618.x

Kraig, K. A., \& Keel, P. K. (2001). Weight-based stigmatization in children. International Journal of Obesity and Related Metabolic Disorders : Journal of the International Association for the Study of Obesity, 25(11), 1661-1666. doi: 10.1038/sj.ijo.0801813

Latner, J. D., \& Stunkard, A. J. (2003). Getting worse: The stigmatization of obese children. Obesity Research, 11(3), 452. doi: 10.1038/oby.2003.61

Lerner, R. M., \& Gellert, E. (1969). Body build identification, preference, and aversion in children. Developmental Psychology, 1(5), 456-462. doi: 10.1037/h0027966

Lerner, R. M., \& Korn, S. J. (1972). The development of body-build stereotypes in males. Child Development, 43(3), 908-920. doi: 10.2307/1127641

Liu, D., Vanderbilt, K. E., \& Heyman, G. D. (2013). Selective trust: Children's use of intention and outcome of past testimony. Developmental Psychology, 49(3), 439.

Lutz, D. J., \& Keil, F. C. (2002). Early understanding of the division of cognitive labor. Child Development, 73(4), 1073-1084. doi: 10.1111/1467-8624.00458

Ma, L., \& Ganea, P. A. (2010). Dealing with conflicting information: Young children's reliance on what they see versus what they are told. Developmental Science, 13(1), 151-160. doi: 10.1111/j.1467-7687.2009.00878.x 
Ma, L., \& Woolley, J. D. (2013). Young children's sensitivity to speaker gender when learning from others. Journal of Cognition and Development, 14(1), 100-119. doi: $10.1080 / 15248372.2011 .638687$

Magiati, I., Dockrell, J. E., \& Logotheti, A. (2002). Young children's understanding of disabilities: The influence of development, context, and cognition. Journal of Applied Developmental Psychology, 23(4), 409-430. doi: 10.1016/S0193-3973(02)00126-0

Martin, C. L., \& Fabes, R. A. (2001). The stability and consequences of young children's samesex peer interactions. Developmental Psychology, 37(3), 431-446. doi: 10.1037/00121649.37.3.431

Nowicki, E. A., \& Sandieson, R. (2002). A meta-analysis of school-age children's attitudes towards persons with physical or intellectual disabilities. International Journal of Disability, Development and Education, 49(3), 243-65. doi:

$10.1080 / 1034912022000007270$

Okagaki, L., Diamond, K. E., Kontos, S. J., \& Hestenes, L. L. (1998). Correlates of young children's interactions with classmates with disabilities. Early Childhood Research Quarterly, 13(1), 67-86. doi: 10.1016/S0885-2006(99)80026-X

Pasquini, E. S., Corriveau, K. H., Koenig, M., \& Harris, P. L. (2007). Preschoolers monitor the relative accuracy of informants. Developmental Psychology, 43(5), 1216-1226. doi: $10.1037 / 0012-1649.43 .5 .1216$

Piaget, J. (1929). The child's conception of the world. New York: Harcourt Brace.

Powlishta, K. K., Serbin, L. A., Doyle, A., \& White, D. R. (1994). Gender, ethnic, and body type biases: The generality of prejudice in childhood. Developmental Psychology, 30(4), 526536. doi: 10.1037/0012-1649.30.4.526 
Rakoczy, H., Warneken, F., \& Tomasello, M. (2009). Young children's selective learning of rule games from reliable and unreliable models. Cognitive Development, 24(1), 61-69. doi: 10.1016/j.cogdev.2008.07.004

Richardson, S. A. (1970). Age and sex differences in values toward physical handicaps. Journal of Health and Social Behavior, 11(3), 207-214.

Richardson, S. A. (1983). Children's values in regard to disabilities: A reply to yuker. Rehabilitation Psychology, 28(3), 131-140. doi: 10.1037/h0090980

Richardson, S. A., Goodman, N., Hastorf, A. H., \& Dornbusch, S. M. (1961). Cultural uniformity in reaction to physical disabilities. American Sociological Review, 26(2), 241247.

Scofield, J., \& Behrend, D. A. (2008). Learning words from reliable and unreliable speakers. Cognitive Development, 23(2), 278-290. doi: 10.1016/j.cogdev.2008.01.003

Scofield, J., Gilpin, A. T., Pierucci, J., \& Morgan, R. (2013). Matters of accuracy and conventionality: Prior accuracy guides children's evaluations of others' actions. Developmental Psychology, 49(3), 432.

Sigelman, C. K., Miller, T. E., \& Whitworth, L. A. (1986). The early development of stigmatizing reactions to physical differences. Journal of Applied Developmental Psychology, 7(1), 17-32. doi: 10.1016/0193-3973(86)90016-X

Spillers, C. (1982). An investigation of children's attitudes towards physically disabled peers. Mid American View of Sociology, 7(1), 55-69.

Staffieri, J. R. (1967). A study of social stereotype of body image in children. Journal of Personality and Social Psychology, 7(1), 101-104. doi: 10.1037/h0021227 
Talwar, V., \& Lee, K. (2002). Emergence of white-lie telling in children between 3 and 7 years of age. Merrill-Palmer Quarterly, 48(2), 160-181. doi:10.1353/mpq.2002.0009

Taylor, M., Cartwright, B. S., \& Bowden, T. (1991). Perspective taking and theory of mind: Do children predict interpretive diversity as a function of differences in observers' knowledge? Child Development, 62(6), 1334-1351. doi:

10.1111/j.14678624.1991.tb01609.x

Tiggemann, M., \& Anesbury, T. (2000). Negative stereotyping of obesity in children: The role of controllability beliefs. Journal of Applied Social Psychology, 30(9), 1977-1993. doi: 10.1111/j.1559-1816.2000.tb02477.x

Tillman, T., Kehle, T. J., Bray, M.A., Chafouleas, S. M., \& Grigerick, S. (2007). Elementary school students' perceptions of overweight peers. Canadian Journal of School Psychology, 22(1), 68-80. doi: 10.1177/0829573507301130

Turnbull, J. D., Heaslip, S., \& McLeod, H. A. (2000). Pre-school children's attitudes to fat and normal male and female stimulus figures. International Journal of Obesity and Related Metabolic Disorders : Journal of the International Association for the Study of Obesity, 24(12), 1705-1706. doi: 10.1038/sj.ijo.0801462

Wei, S., \& Di Santo, A. (2012). Preschool children's perceptions of overweight peers. Journal of Early Childhood Research, 10(1), 19-31. doi: 10.1177/1476718X11407411

Weil, W. B. (1977). Current controversies in childhood obesity. The Journal of Pediatrics, 91(2), 175-187. doi: 10.1016/S0022-3476(77)80809-3

Wellman, H. M., Cross, D., \& Watson, J. (2001). Meta-analysis of theory-of-mind development: The truth about false belief. Child Development, 72(3), 655-684. doi: 10.1111/14678624.00304 
Wilson, R. K., \& Eckel, C. C. (2006). Judging a book by its cover: Beauty and expectations in the trust game. (2006). Political Research Quarterly (Formerly WPQ), 59(2), 189-202. doi:10.1177/106591290605900202 